Article

\title{
Comparative Life Cycle Assessment of Glucose Production from Maize Starch and Woody Biomass Residues as a Feedstock
}

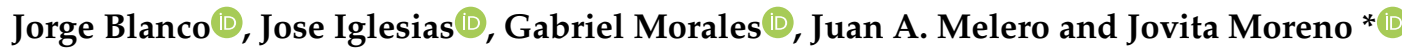 \\ Chemical \& Environmental Engineering Group, Universidad Rey Juan Carlos, Tulipán s/n, 28933 Madrid, Spain; \\ jorge.blanco@urjc.es (J.B.); jose.iglesias@urjc.es (J.I.); gabriel.morales@urjc.es (G.M.); juan.melero@urjc.es (J.A.M.) \\ * Correspondence: jovita.moreno@urjc.es
}

Received: 15 February 2020; Accepted: 21 April 2020; Published: 24 April 2020

check for updates

Featured Application: Glucose is a key intermediate in many routes of biomass transformation to obtain valuable bio-products. The sustainability of glucose production is essential to improve the environmental profile of 'greener' bio-products. In this work, LCA methodology was used to determine the strengths and weaknesses of processes devoted to glucose production, starting from different types of biomass. Alternatives to reduce the environmental impacts of glucose generation are highlighted from our LCA results.

\begin{abstract}
The sustainability of glucose production from two different feedstocks, maize starch (MS) and woody biomass residues (WBR), was evaluated by means of life cycle assessment (LCA) methodology. The aim of this work was to compare the environmental performance of conventional technology (glucose from MS by enzymatic hydrolysis) with a novel alternative (glucose from WBR by a three-step process: pretreatment-crushing, deacetylation, and diluted-acid treatment-; conditioning -acid-alkali-acid treatment-; and enzymatic hydrolysis), which is specifically oriented towards the circular economy context. Life cycle inventory was completed by simulation of the different processes, followed by integration of the mass and energy inputs and outputs in an LCA software (GaBi 7.3). LCA results evidenced benefits in all the evaluated environmental impacts when using WBR as a glucose source alternative. Environmental damages associated with the starch production process, which involves more than $60 \%$ of the impacts calculated for glucose production from maize starch, has been detected as the key step in which focusing the improvement efforts for this process. On the other hand, pretreating of the biomass residues was the most contributing stage in the WBR process, principally due to the large heat and electricity requirements associated with this stage. Finally, we concluded that the WBR process proposed here might be considered as a valuable alternative in sustainability terms for the production of glucose within the biorefinery concept. Likewise, we have identified the critical points that should be considered to further improve this technology.
\end{abstract}

Keywords: bio-refinery; sustainability; glucose production; LCA; woody biomass residues

\section{Introduction}

Within the bio-refinery concept, glucose is probably one of the key starting raw materials because its abundance in lignocellulosic biomass, and the high chemical versatility of this carbohydrate to be transformed into a wide variety of bio-products through different chemical pathways (isomerization, dehydration, hydrogenation, oxidation, etc. and/or their combinations) $[1,2]$. Nowadays, glucose is industrially produced by hydrolysis of amylaceous feedstock under acid conditions or by using specialized enzymes. Conventionally, starch-containing raw materials like potato, maize, wheat, and 
cassava are some of the crops frequently used for its production [3]. In this sense, environmental impacts associated to the production of starch, and the derived glucose, are affected by agricultural stages, which usually involve intensive consumption of natural resources (land occupation and transformation, use of fertilizers and pesticides, depletion of fossil fuels for machinery, etc.). In this context, an interesting alternative for improving the environmental profile of glucose is its production from residual biomass, an option which also avoids competition with the food market. The potential benefits of such an alternative has prompted several investigations focused on the conversion of a variety of residual biomass into glucose [4]. Li et al. (2007) [5] studied the transformation of the biodegradable fraction of municipal solid wastes into glucose, comparing different pre-hydrolysis and enzymatic hydrolysis treatments. Specific food residues have also been used by some authors to produce glucose through both chemical and enzymatic pathways [6-9], evidencing the benefits of the latter because of the lower downstream requirements for recovering glucose. Other studies have also reported the treatment of various types of paper wastes by enzymatic processes [10] showing, among other remarkable conclusions, that non-recyclable paper can be used to obtain high-purity glucose syrups.

Despite the significant examples above, lignocellulosic biomass residues are undoubtedly the most common type of waste tested for glucose production, mainly because of its renewable character and availability $[4,11]$. Waste lignocellulosic biomass includes a huge number of different feedstock, such as agricultural wastes, woody wastes, residues from green areas, etc. However, the recalcitrance and complex composition of these feedstocks make the selective transformation of their constituting components (cellulose, hemicellulose, and lignin) into the corresponding monomers (e.g., glucose, xylose, aromatics) a challenge, and much more difficult than converting simpler and less recalcitrant residues. The recalcitrance of waste lignocellulosic biomass can be reduced through high-temperature and/or pressure conditioning steps (e.g., steam explosion technology) or advanced treatments using ionic-liquids [12,13]. On the other hand, the complex composition of natural lignocellulosic biomass wastes requires an adequate separation technology [14], either applied to the starting biomass constituents (fractionation) or the complex mixtures obtained after biomass transformation (monomers, oligomers, aromatic compounds, and other extractable substances). Therefore, the conversion of lignocellulosic biomass wastes to get simple monosaccharides selectively and efficiently results in a complex process, whose environmental impacts and resources requirements should be quantified to evaluate its real sustainability as compared to conventional pathways for sugar monosaccharides production.

LCA methodology has been previously applied to the environmental evaluation of the transformation of lignocellulosic biomass into valuable bio-products such as bioethanol [15], biofuels [16], bioenergy [17], or jet-fuel [18]. However, a great part of these investigations is focused on valorizing biomass coming from conventional crops (instead of residues) and/or these are directly focused on the environmental impacts of the final products, paying little attention to the production and purification of the intermediate sugar monosaccharides. Other authors, such as Renouf et al. (2008) [19], Tsiropoulos et al. (2013) [20], Moncada el al. (2018) [21], Salim et al. (2019) [22], and Moreno et al. (2020) [2], reported LCA results focused on the production of sugar monosaccharides and their refining, but starting from non-residual raw materials (mainly maize and wheat grains). Thus, there are still few studies in the literature devoted to ascertaining the environmental profile of glucose coming from lignocellulosic biomass wastes. One of the most relevant pieces of research in this field is the work of Morales et al. (2017) [23], who evaluated different technologies for glucose production using highly recalcitrant softwood residues. LCA results were compared with those achieved in the conventional process for glucose production, based on sugarbeet as starting feedstock. Results suggested that, for all the evaluated scenarios, softwood biomass involves higher environmental impacts than sugarbeet when used as starting raw materials. This is an expected conclusion because of the complexity and recalcitrant nature of the residual woody biomass used in this research. Nevertheless, when the agricultural stages of conventional crops, such as sugarbeet, are included in the LCA study, results are not too unfavorable for the woody waste alternative. 
This work aims to compare the environmental impacts associated with the production of glucose through the treatment of both maize starch and woody residual biomass, using an LCA cradle-to-gate approach. In both cases, a similar enzymatic process was used for cellulose depolymerization but, according to the diverse nature of each raw material, very different pretreatment and conditioning steps were considered, leading to interesting differences. Likewise, the influence of the agricultural phases necessary for starch production is confronted with the residual origin of the woody biomass.

\section{Materials and Methods}

\subsection{Goal \& Scope}

The goal of this study was to determine the environmental performance of the production of glucose from lignocellulosic biomass, comparing two different technologies within the life cycle assessment (LCA) framework: maize starch based process (MS-bp) and woody biomass residues based process (WBR-bp). The functional unit defined to this matter was the production of $1 \mathrm{~kg}$ of glucose in aqueous solution ( $5 \mathrm{wt} \%$ ). The considered system boundaries correspond to a cradle-to-gate approach since glucose utilization is not taken into account. The maize starch cultivation was considered, but for the sake of clarity, biogenic $\mathrm{CO}_{2}$ uptake was excluded from the study in both cases. This simplified the comparison, given the difficulties for gathering biomass-growth reliable datasets. The system boundaries of both processes are shown in Figures 1 and 2.

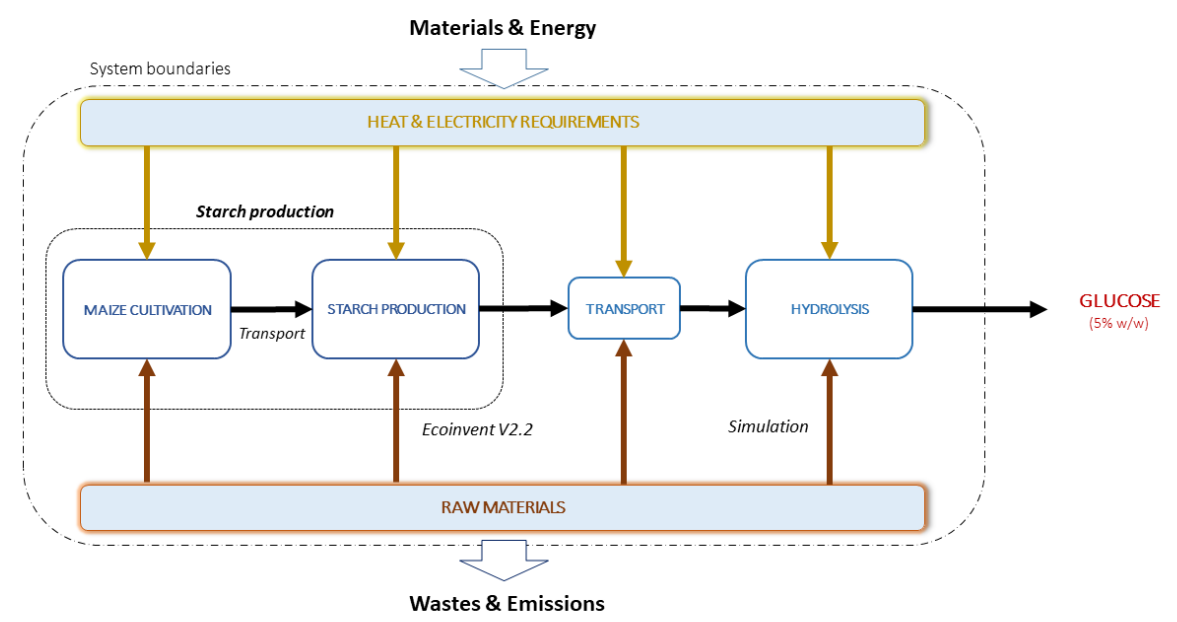

Figure 1. System boundaries for the maize starch based process (MS-bp).

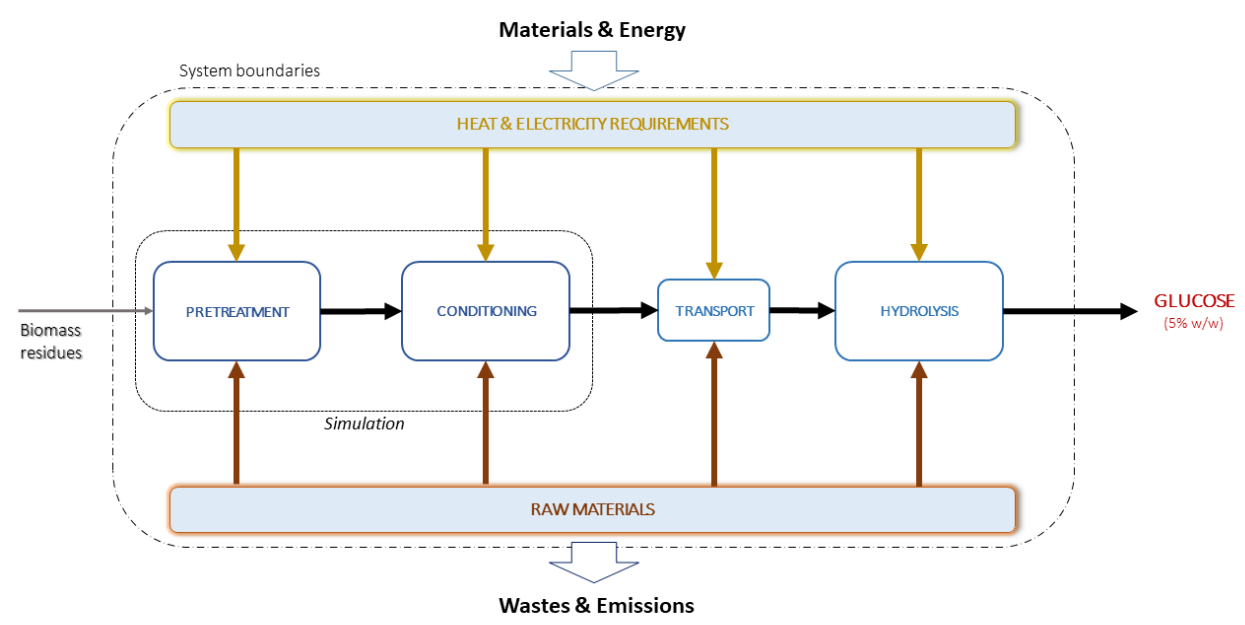

Figure 2. System boundaries for the woody biomass residues based process (WBR-bp). 
Allocation methods were not applied, even though these processes typically yield profitable secondary products [20] since the aim was comparing, and not to describe, a specific environmental profile. The absence of those considerations should be kept in mind when interpreting the LCA results, most importantly, in the case of the woody biomass residues based process (WBR-bp) [24].

\subsection{Life Cycle Inventory (LCI)}

Data for the life cycle inventory were collected from three different sources. First, technical literature and patent documents were used for the simulation of biomass pretreatment, conditioning of the pretreated biomass, and hydrolysis processes. Also, energy and material outputs were obtained from the computational simulation performed with Aspen plus V10, a chemical process simulation software. Finally, auxiliary incomes, raw material information, and starch production processes were selected from the Ecoinvent 2.2 database. All these data were implemented in the LCA software GaBi V7.3. Particular processes and considerations are detailed below.

\subsubsection{Maize Starch-Based Process}

The considered process for glucose production from maize starch consists of two steps. First, maize grains are harvested and transported to the starch production plant, where they undergo several transformations to separate the germ, fiber, gluten, and finally, starch. This is subsequently stabilized and stored for its further hydrolysis in the glucose manufacturing plant.

Since the starch production was implemented from the Ecoinvent database, it was integrated as a black box process within the entire glucose production system. The process, as described in the Ecoinvent report about agricultural production systems [25], consists of the transport of the maize grains to the starch production plan, followed by a first stage devoted to the separation of the impurities. The grains are soaked at $50^{\circ} \mathrm{C}$ for $40 \mathrm{~h}$, and the wet mixture is subsequently milled while the germ is recovered for oil extraction. The starch is mechanically separated and dried, both mechanic and thermally, to get a final water content of $14 \mathrm{wt} \%$. The hydrolysis process was assumed as a mutual step in both the MS-bp and WBR-bp alternatives, and it is further described in Section 2.2.3.

\subsubsection{Woody Biomass Residues Based Process}

Glucose production from lignocellulosic biomass is still a novelty, which has been the focus of several studies over the last years. The most challenging issue that needs to be overcome is the pretreatment of the biomass, which has been proven to be crucial for the correct performance of the processes downstream. Intending to provide comparable results, the selected pretreatment step was the multistage (deacetylation-delignification-acid treatment) process reported by the National Renewable Energy Laboratory (NREL) in 2015, which is considered as a reference due to its wide scope. This study was published in a very complete report containing numerous operation details that allowed the conduction of our simulations for obtaining the necessary data for the life cycle inventory (LCI) [26]. After the pretreatment, an additional conditioning step was applied to increase the purity of cellulose and enhance the performance of the later hydrolysis step, as described in the patent document WO 2017/013684 Al [14]. This hydrolysis process was selected because it is based on an enzymatic pathway (which does not require subsequent neutralization steps) and makes use of filtration operations for purification steps (which generally consume less energy than other alternatives). An detailed description of these processes is provided below.

As starting material, a generic woody biomass composition has been considered according to Dietrich [27], having a moisture content of $30 \mathrm{wt} \%$ (see more details in Tables S1 and S2 of the Supplementary Information). Before the first reaction step, the biomass was crushed to produce wood chips, which were fed into a deacetylation tank, along with sodium hydroxide for lignin solubilization. The resultant black liquor was removed, and the retained mixture was forced through high-compression screw feeders, that discharge into a vertical acidification tank. Water steam and sulfuric acid were added for further oligomer disruption. The content was conveyed to a flash tank where the solubilized 
lignin was condensed and eliminated before a final neutralization stage with ammonia gas. A more detailed description can be found in NREL's study [26]. Although, as previously mentioned, when any allocation method was applied, it must be noted that we had considered hemicellulose carbohydrates to be transformed into soluble sugars under the pretreatment conditions, leading to different monomeric products at the end of the process.

The pretreated biomass was then submitted for conditioning, undergoing a three-step acid-alkali-acid treatment to increase cellulose purity (Figure 3). The first acid treatment was conducted in the presence of a $2 \mathrm{wt} \%$ sulfuric acid aqueous solution at $393 \mathrm{~K}$ and atmospheric pressure for $15 \mathrm{~min}$. This stage was intended to partially affect insoluble lignin and xylan, and the result was a slurry, which was forced through a mechanical filter resulting in two streams. The undesired liquid fraction was removed and sent to wastewater treatment, whereas the solid fraction (containing at least $80 \%$ pure cellulose) was treated with sodium hydroxide ( $0.5 \mathrm{wt} \%$ ) for $30 \mathrm{~min}$ to undertake a second reaction under similar conditions to those above described for the first stage. After a second separation operation, the third cycle, a new acid treatment with $2 \mathrm{wt} \%$ sulfuric acid solution, took place, yielding a final aqueous suspension $(7 \mathrm{wt} \%)$ containing highly-pure cellulose $(98 \mathrm{wt} \%)$.

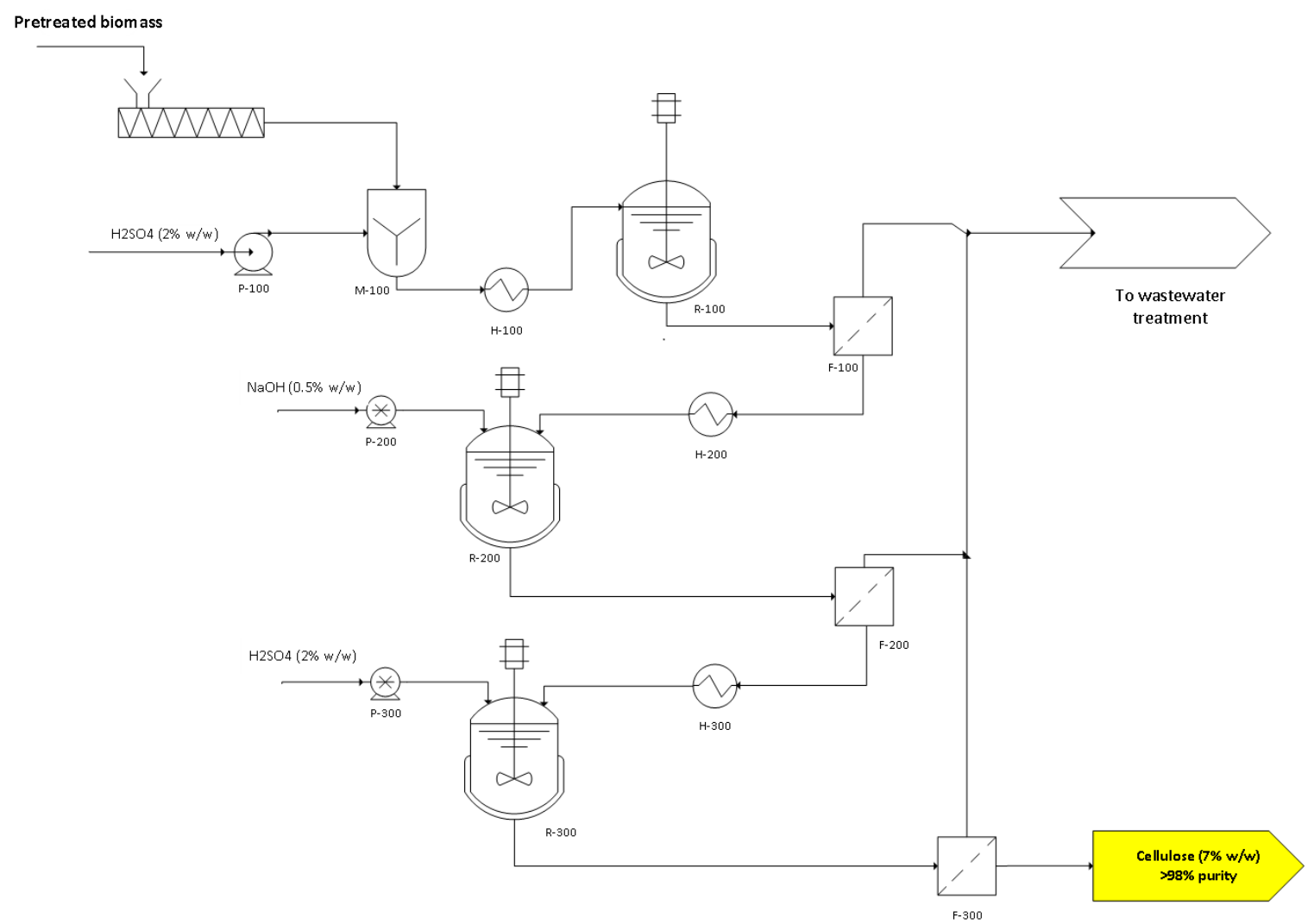

Figure 3. Process flow diagram for the acid-alkali-acid conditioning of the pretreated biomass based on reference [14] (equipment designation: P-X00, impulsion pump; M-X00, mixing vessel; H-X00, heat exchanger; R-X00, reactor; F-X00, membrane operation unit).

\subsubsection{Hydrolysis}

Hydrolysis of cellulose is the direct way for glucose production from this polysaccharide. As mentioned above, this stage was equal in the two considered alternatives and simulated as described within the patent WO 2017/013684 Al [14]. An important assumption in this regard is that starch was considered to act like a cellulose molecule in operational terms, given that the only difference is the $180^{\circ}$ rotation of the bonds between the glucose units. 
The enzymatic hydrolysis consists of the systematical depolymerization of the cellulose, based on the use of enzymes to promote the selective cleavage of glucosidic bonds to produce glucose monomers. The process is divided into two steps, each of them controlled by a different enzyme, namely a cellulase for amylose axial bonding, and a $\beta$-glucosidase for amylopectin linear units. A detailed description of the process can be found in our previous study [2].

\subsection{Life Cycle Impacts Assessment}

The methodology used for the evaluation of environmental impacts was ReCiPe 1.07. Six midpoint indicators were chosen as characterization factors, aiming to provide more accurate results. These factors were the following: climate change (CC), fossil depletion (FD), human toxicity (HT), ozone depletion (OD), particulate matter formation (PMF), and terrestrial acidification (TA).

\subsection{Assumptions and Limitations}

Several considerations were assumed for the simplification of the analysis of impacts. The most significant are listed below:

- The fixed $\mathrm{CO}_{2}$ by the growth of biomass (either maize crops or wood) was excluded from calculations. The principal reason was the difficulty of obtaining reliable data, and the consequent deviations generated in the comparative LCA.

- The physical and chemical properties of cellulose were used for the simulation of the starch hydrolysis process, given the similarities between the two polymers.

- Potential uses for the lignin streams have not been included in the scope of this work, as well as the impacts derived from wastewater treatment processes.

- Secondary products and allocation methods were not considered. This involved both systems that were evaluated under the worst environmental scenario since the impacts are not shared with the by-products obtained in the processes. At this point, it must be taken into account that the Ecoinvent 2.2 database includes an allocation method for the maize starch production process. Specifically, the applied economic allocation assigns $83 \%$ of the environmental impacts on starch. Despite this fact slightly affects the absolute values of the mid-point indicators obtained for the maize system and comparative LCA results are barely influenced, it has been taking into account for calculations. Thus, mid-point indicators of MS-bp were obtained, excluding the allocation method considered within the Ecoinvent 2.2 database. For comparison purposes, values of mid-point indicators of MS-bp showed in the supporting information are presented in both ways (with and without allocation).

- Procedures downstream of the hydrolysis stage, such as the purification of the glucose, were not included in the scope of this analysis. Purification main impacts arise from the evaporation of the exceeding process water to reach a suitable product concentration for commercial applications [2]. As identical starting and end concentrations of the glucose solutions in both analyzed processes would lead to identical results, this stage has not been considered.

- Other auxiliary processes, such as wastewater treatment, heat integration, or solid combustion, were not taken into account.

\section{Results}

\subsection{Maize Starch-Based Process (MS-bp)}

The first alternative to be evaluated was the production of glucose from maize starch, considered as the benchmark because of its widespread use in the current industry. Figure 4 depicts the influence of the different stages in several environmental impact categories, starch production being the most relevant one, as it accounts for the major contributions to all the evaluated environmental impacts (higher than $60 \%$ for all of them). The hydrolysis stage led to relevant contributions to the OD (ozone 
depletion), FD (fossil depletion), and CC (climate change) categories. These results are related to the low starch concentration required for the enzymatic hydrolysis reactors (5 wt\%) [2], a quite typical feature of biotechnological processes, which involves significant energy requirements for water heating to the optimal operating temperature for enzymes.

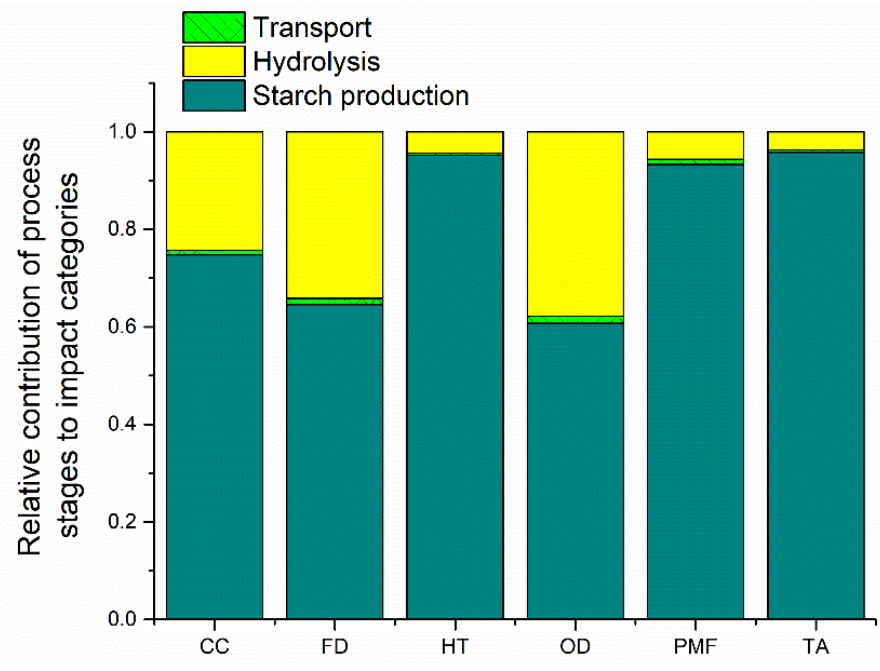

Figure 4. LCA results obtained for the relative contribution of process stages to the evaluated impact categories in glucose production from maize starch.

As for transportation, this is only referred to the transference of the starch to the glucose production plant, being the primary maize grains transportation included in the starch production process, as explained in Section 2.2.1. Contributions of this stage are better appreciated in Figure 5, in which the starch production has been removed from the analysis, allowing it to perform a more comprehensive analysis of the rest of the process. At this juncture, transportation contributed to $10 \%$ of the overall impact on the acidification (TA) and toxicity (HT) indicators and more than $15 \%$ of the particle formation (PMF) category, due to the emissions coming from the diesel engines used in the used load transportation media.

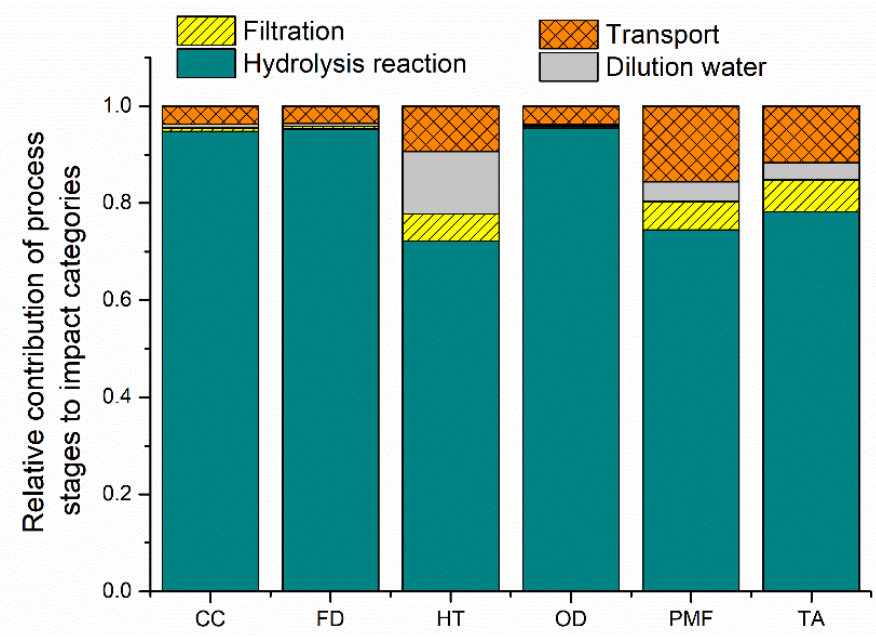

Figure 5. LCA results obtained for the relative contribution of process stages to the evaluated impact categories in glucose production from maize starch, excluding starch manufacture.

Besides transportation, Figure 5 depicts the contribution of some sub-processes considered in the hydrolysis stage: filtration units (ultrafiltration and nanofiltration), dilution (used to adjust the concentration of solids) and the hydrolysis reaction itself. These results confirmed the relevant influence 
of the reaction steps, due to the heating needs of the hydrolysis reactors. Unexpectedly, despite the huge amount required to reach the required solids concentration, the use of water for dilution during the hydrolysis stage also revealed to exert an important contribution to the human toxicity (HT) indicator when starch is not considered. This fact is related to some input flows of the inventory of the water generation process existing in the Ecoinvent v2.2 database. More information about this inventory is provided in the supporting information (see Table S8).

\subsection{Woody Biomass Residues Based Process (WBR-bp)}

Results obtained in the LC analysis of the glucose production process using woody biomass residues as starting material (Figure 6) showed that the pretreatment stage of the starting biomass was the most relevant one, contributing to $50 \%-70 \%$ of the overall impact in all the category indicators. The severe operating conditions required for the pretreatment of wood biomass are the most plausible explanation for the significant impact caused by this stage.

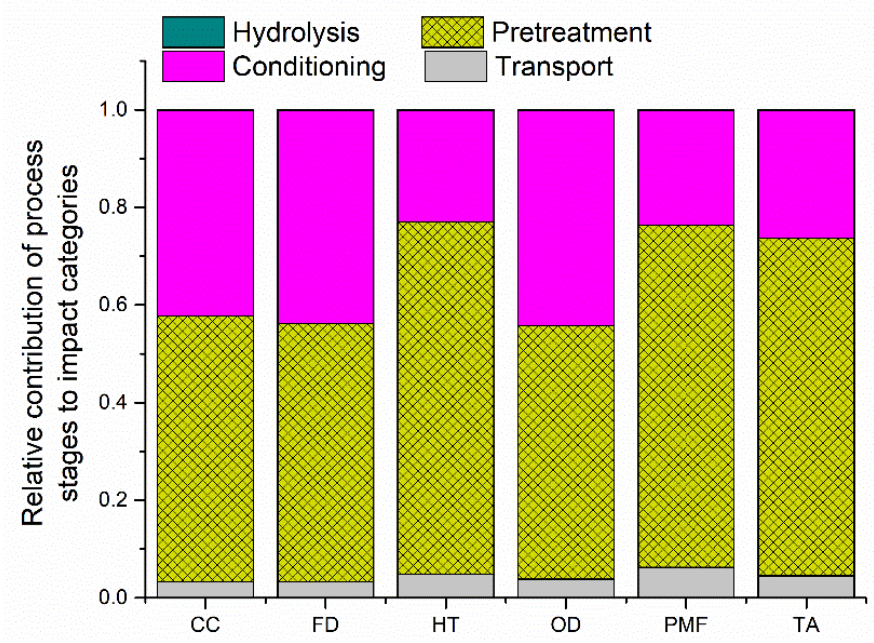

Figure 6. LCA results obtained for the relative contribution of process stages to the evaluated impact categories in glucose production from woody biomass residues.

Together with the pretreatment stage, the conditioning of biomass is almost as relevant in the categories of climate change (CC), fossil depletion (FD), and ozone depletion (OD). In this case, the requirement to operate at low solid concentrations in combination with positive high-temperature conditions leads to an elevated heat duty, being the main responsible for most of these impacts.

The contribution of the hydrolysis process in the WBR process to the environmental impact of this option for glucose production is almost negligible. This involves a significant difference as compared to the starch-based process (see Figure 4), which is caused by the existence of the conditioning step in the woody biomass residues process. Since the temperature conditions are higher in the conditioning step than in the enzymatic hydrolysis stage, the cellulose concentration being quite similar $(\sim 7 \mathrm{wt} \%)$, the impacts associated to the energy consumption are transferred from the hydrolysis to the conditioning stage, as it is in this latter where the process stream is warmed up to the operating conditions.

Transportation of raw materials, based on our calculations, has a minor influence on the waste woody biomass process. However, further investigation should be performed to determine the implications involved in the biomass gathering and transportation, as unlike in the MS-bp case, some types of biomass waste are usually found as a scattered resource, increasing the environmental and logistic costs of its recovery and transportation to the processing plant.

A detailed analysis of the pretreatment and conditioning steps has been performed because of their large contribution, in all the studied categories, to the environmental impact of the WBR-bp case. Results are included in Sections 3.2.1 and 3.2.2. 


\subsubsection{Pretreatment of Lignocellulosic Biomass}

For streamlining purposes, pretreatment sub-steps have been divided into three groups, attending to the order they are performed. Thus, the deacetylation stage refers to the sodium hydroxide treatment; the reaction step involves the operations of high-pressure screw feeding and sulfuric acid addition; finally, the purification step includes flash evaporation and ammonia neutralization. A second classification has been established attending to the inputs to the system, namely heat, electricity, and reactants requirements.

Figure 7a depicts the LCA results for the pretreatment stage in the process for glucose production from woody biomass residues. The purification step exerts a significant influence (i.e., greater than $50 \%$ [28]) over the overall impact on the categories of climate change (CC), fossil depletion (FD), and ozone depletion (OD). Similarly, heating is responsible for $77-90 \%$ of the relative contribution in the same indicators, as shown in Figure $7 \mathrm{~b}$. These results allow us to spot a relation between the environmental impacts caused by the pretreatment step and the heat duties required for the purification sub-step, mainly arising from the flash evaporator unit.

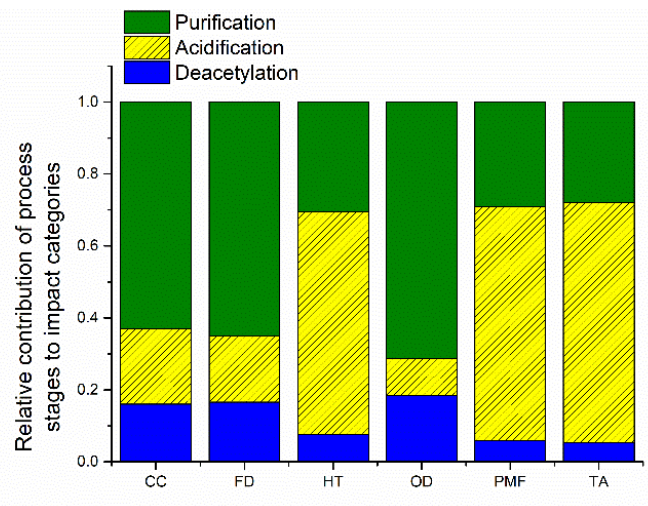

(a)

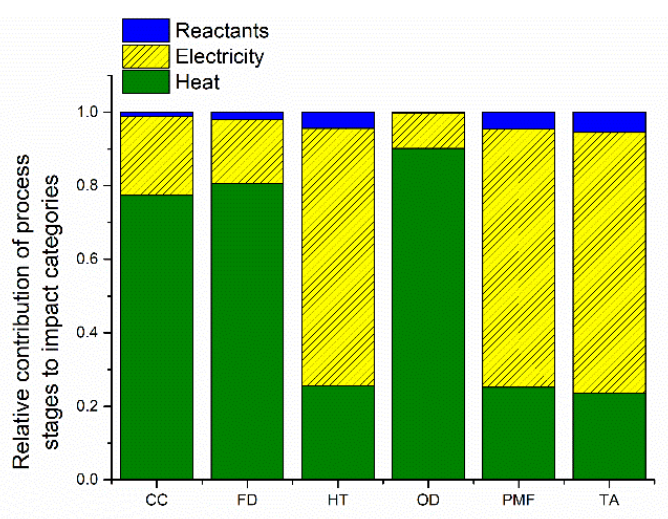

(b)

Figure 7. The relative contribution of process stages and inputs to the evaluated impact categories in LCA results obtained for the pretreatment stage in glucose production from woody biomass residues.

(a) Impact aggregation by sub-process; (b) impact aggregation by input.

Similarly, a direct relationship can be established between the impact profiles of the reaction stage and its electricity requirements. The contribution of this sub-step to human toxicity (HT), particulate matter formation (PMF), and terrestrial acidification (TA) categories are derived from the high electricity incomes required by the high-compression screw feeders.

On the other hand, the deacetylation sub-step showed little influence on the overall impacts related to the pretreatment, which makes it a very favorable step concerning the benefits derived from its application [26].

\subsubsection{Conditioning}

A similar treatment of the data described above in the previous section, has been established for the environmental impacts caused by the conditioning step and all its sub-steps (see Figure 8). Included sub-steps are the two acid treatments (together considered), alkali treatment, and membrane separation. The inputs are the same already described for the pretreatment stage.

The main impacts caused by the conditioning step are ascribed to the acid and basic reaction treatment sub-steps, dealing with the upgrading of the pretreated biomass. In the case of the indicators affected in a higher extension by heating requirements (climate change, CC; fossil depletion, FD; and ozone depletion, OD), the basification step is the one contributing with a major proportion. This could 
be attributed to the higher energy needings of the alkaline treatment to keep the reaction temperature under control for longer times (see Section 2.2.2). On the other hand, terrestrial acidification (TA) is mainly caused by acid steps, since acid media is achieved employing sulfuric acid.

Despite the effects of reactants' consumption on some indicators, especially terrestrial acidification (TA) and particle matter formation (PMF). heating requirements appear to be, by far, the essential weakness of this process from an environmental perspective. Separation operations, on their part, showed a minor effect in the human toxicity category, with negligible contributions to the rest of the indicators.

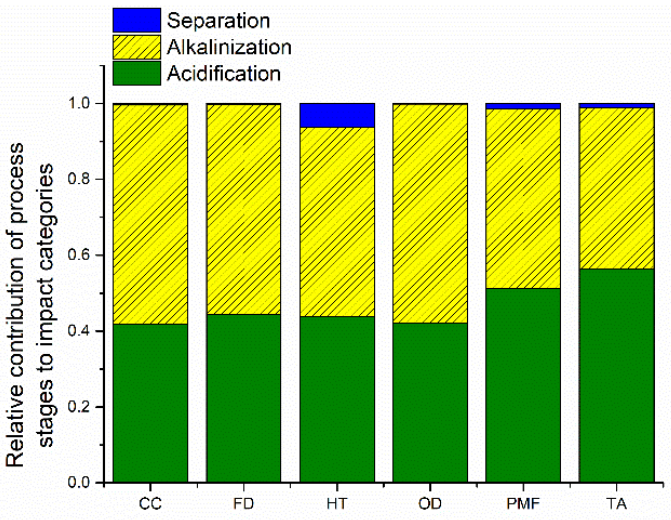

(a)

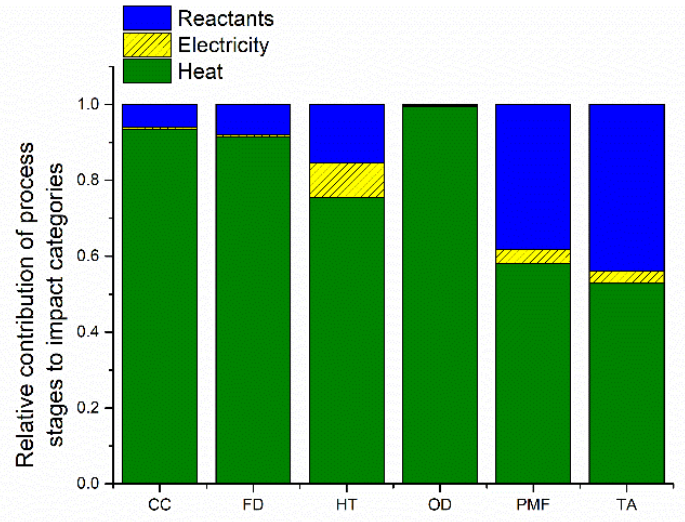

(b)

Figure 8. The relative contribution of process stages and inputs to the evaluated impact categories in LCA results obtained for the conditioning stage in glucose production from woody biomass residues.

(a) Impact aggregation by sub-process; (b) impact aggregation by input.

\subsection{MS-bp and WBR-bp Comparison}

An overall comparison between the environmental performance shown by the two analyzed alternatives for glucose production is summarized in Figure 9. Also, values of ReCiPe mid-point indicators are detailed in Tables S3 and S4 of the Supplementary Information. Results indicate that the WBR based-process involved an improvement in the six environmental impacts under study. The categories showing the largest differences in the environmental impacts caused by both processes were human toxicity (HT), particle matter formation (PMF), and terrestrial acidification (TA), showing with a relative contribution below $30 \%$ for the WBR-bp case as compared to the MS-bp option.

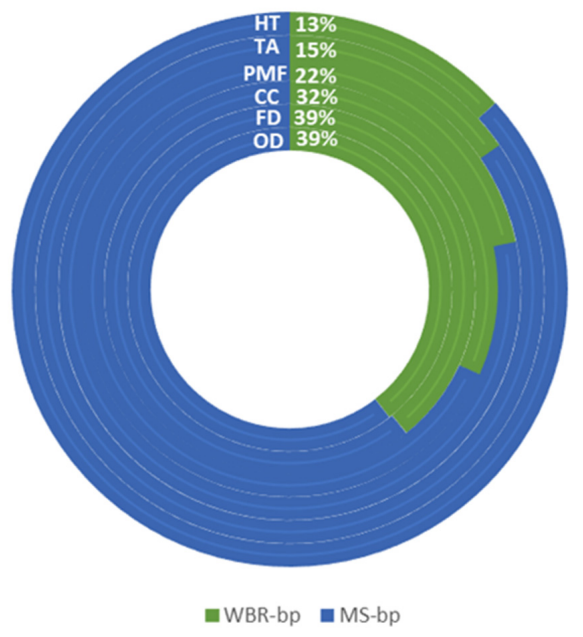

Figure 9. Relative contribution to the studied environmental categories of MS and WBR based processes. 
On the other hand, fossil depletion (FD) and ozone depletion (OD) categories present the lowest relative gap between the two options, being calculated a 39\% for the woody biomass system versus $61 \%$ for the starch case.

Regarding climate change (CC), a promising reduction of carbon dioxide emissions was achieved by using woody biomass residues as the glucose source instead of maize starch: $0.8 \mathrm{~kg} \mathrm{CO}$-eq $/ \mathrm{kg}$ of glucose versus $1.76 \mathrm{~kg} \mathrm{CO}$-eq/ $\mathrm{kg}$ (see Tables S3 and S4); this evidences the enormous potential of glucose production from lignocellulosic woody biomass as the most reliable option for decreasing $\mathrm{CO}_{2}$ emissions.

\section{Discussion}

The studied environmental impact categories (Figure 9) can be divided into two groups: indicators clearly more affected by the MS-bp system (HT, PMF, and TA, with a relative contribution of the WBR-bp lower than 30\%), which will be classified as cluster A for further discussion, and indicators closer for both systems (CC, FD, and OD, with a relative contribution of the WBR-bp higher than $30 \%$ ), which will be included in cluster B.

Attending to the results obtained for the LCA study on MS-bp, the main drawback ascribed to this process came from the production of the starting raw material, starch, with $60-96 \%$ of the relative contribution in all the studied impact categories. Previous studies assigned an influence around $70 \%$ to the starch manufacture within the environmental footprint of glucose production from this polysaccharide [3], relative to carbon footprint and water depletion indicators. Indeed, starch manufacture accounts for most of the generated impacts even when considering the transformation of the glucose into other products. Accordingly, we have previously reported the large influence associated with starch production on the glucose chemical and enzymatic synthesis routes, and the prevalence of those impacts when considering the subsequent glucose hydrogenation to produce sorbitol [2]. Similarly, Akmalina determined that within the production of sorbitol, at least $60 \%$ of the impacts came from the production of glucose in every category described [29].

In this sense, the agricultural phase is associated with severe environmental weaknesses due to the land transformation, large area occupation, elevated water consumption, use of pesticides, fertilizers, machinery, etc. Similarly, field emissions and agricultural production of comparable raw materials used in sugar production have been noted to withhold greater potential for acidification, eutrophication, or greenhouse emissions than the subsequent processing [19]. Since the agricultural phase appears to be responsible for most of the impacts in the MS-bp, WBR-bp has the potential to constitute a more sustainable alternative by substituting the agricultural issues by the use of wastes. Considering the results shown in Figure 9, the impacts caused by the application of pretreatment and conditioning processes seem to be lower than those produced by the cultivation and harvesting of the maize crops.

Regarding the pretreatment of the biomass of the WBR-bp, it has been the focus of a large number of studies over the past years $[30,31]$. One of the challenges for pretreatment technologies is to develop scalable and efficient processes with low energy requirements [32]. However, the reported alternatives to conduct the depolymerization of the complex structural components of wood, still show large environmental impacts associated. Accordingly, the pretreatment stage was the one with the highest contribution to the impact categories produced in WBR-bp. Relative contribution varied from $50 \%$ to $70 \%$ and was superior to $65 \%$ in all the categories considered in cluster A (see Figure 6). Specifically, cluster A indicators are mostly affected by screw feeders used for displacing the mixture from the deacetylation tank to the acidification reactor (see Section 3.2.1). This operation involves a very large consumption of electricity due to the difficulties for moving the highly viscous biomass slurry (despite previous deacetylation treatment, the substrate is still rich in insoluble and highly interconnected structural polymers, which confers it a high viscosity).

On the other hand, purification sub-processes used in the pretreatment step, namely flash evaporation and ammonia neutralization, prevail as the most impacful sub-steps in those indicators 
included in cluster B (see Figure 7a). In this sense, the flash tank should be noted as the critical equipment of the purification section to cluster $B$ indicators due to its operational heat requirements.

With regards to the conditioning stage of woody biomass, it is known that it favors cellulose breakage, leading to more efficient conversion of the evolving cellulose to glucose during the hydrolysis process. As mentioned above, the heat requirements to maintain the temperature conditions during the acid-alkali-acid treatments are energetically expensive (see Section 3.2.2). In this sense, the reduction in the environmental impact of the easier hydrolysis step should compensate those caused by the biomass conditioning stage to get real improvements in this process. The positive influence of the conditioning stage is plain in Table S7 (Supplementary Information), where it is clear that the reduction of the contribution to impact indicators of the hydrolysis, caused by the conditioning stage, compensates those caused by the higher energy demand of the conditioning treatment. This makes it evident that the presence of the conditioning stage is very convenient to improve the environmental profile of the WBR scheme.

As for the hydrolysis step, the enzymatic reaction appears to be the critical spot in the MS-bp, apart from starch production (Figure 5). This is mainly related to the low concentration of solids required for enzymatic operations. Since a significant amount of water is used, this has a notorious effect on the heating of the mixture to the reaction temperature and makes it necessary to have larger unit operation equipment. However, most of this effect is linked to the first reaction step, since the second one only receives the permeate solution containing the unreacted components arising from the previous phase.

\section{Conclusions}

The key step in the production of glucose from an environmental viewpoint is, in agreement with previous studies; the starch manufacture, accounting for more than $60 \%$ of the overall impact in all the studied environmental categories. The hydrolysis stage (based on an enzymatic pathway) leads to relevant contributions to ozone depletion, fossil depletion, and climate change categories, mostly due to significant heating requirements. In the case of the production using woody biomass residues as a starting substrate, a three-step process was considered: pretreatment (crushing, deacetylation, and diluted-acid treatment), conditioning (acid-alkali-acid treatment), and enzymatic hydrolysis. The pretreatment of lignocellulosic materials proved to be the critical phase due to both heating and electricity supplies. On the other hand, the hydrolysis step presented a much-reduced impact on the selected indicators, compared to the starch-based conventional process. In this sense, conditioning helps to get a more efficient depolymerization reaction and allows to considerably reduce the environmental impacts of hydrolysis, being a useful stage for the WBR scheme. Finally, it must be highlighted that the process based on woody biomass residues introduces promising improvements in the environmental performance of glucose production as compared to the conventional technology (based on starch) due to bypassing of the agricultural phase. However, further investigations should be performed to determine the influence of relevant variables related to the environmental profile of biomass wastes, such as their composition, gathering, transportation, and, especially, use of the generated residues and by-products (such as lignin streams).

Supplementary Materials: The following are available online at http://www.mdpi.com/2076-3417/10/8/2946/s1, Table S1: Initial composition of the biomass used in the simulation of the woody biomass residues based process, Table S2: Hemicellulose composition referred to total biomass, Table S3: Impacts generated in maize starch based process (MS-bp), Table S4: Impacts generated in woody biomass residues based process (WBR-bp), Table S5: Impacts during pretreatment within WBR-bp, Table S6: Impacts during conditioning within WBR-bp, Table S7: Comparison between hydrolysis stage of MS-bp and (hydrolysis + conditioning) stages of WBR-bp, Table S8: Analysis of the human toxicity (HT) indicator of the water production process (water is used for dilution in the hydrolysis stage of both systems).

Author Contributions: The different authors have contributed to this manuscript as follows: conceptualization, J.I. and J.M.; funding acquisition, J.I., G.M., and J.A.M.; investigation, J.B. and J.M.; methodology, J.B. and J.M.; project administration, J.I., G.M., and J.A.M.; resources, J.I., G.M., and J.A.M.; software, J.B. and J.M.; supervision, 
J.I. and G.M.; writing—original draft, J.B. and J.M.; writing—review and editing, J.B., J.I., and J.M. All authors have read and agreed to the published version of the manuscript.

Funding: This research was funded by the Spanish Ministry of Science, Innovation, and Universities (project RTI2018-094918-B-C42), and from the Regional Government of Madrid (project BIOTRES-CM P2018/EMT-4344). J. Blanco kindly acknowledges the Regional Government of Madrid for a research contract (PEJD-2017-PRE/AMB-4510) funded through the European Social Fund.

Conflicts of Interest: The authors declare no conflict of interest.

\section{References}

1. Delidovich, I.; Palkovits, R. Catalytic Isomerization of Biomass-Derived Aldoses: A Review. ChemSusChem 2016, 9, 547-561. [CrossRef]

2. Moreno, J.; Iglesias, J.; Blanco, J.; Montero, M.; Morales, G.; Melero, J.A. Life-cycle sustainability of biomass-derived sorbitol: Proposing technological alternatives for improving the environmental profile of a bio-refinery platform molecule. J. Clean. Prod. 2020, 250, 119568. [CrossRef]

3. Vercalsteren, A.; Boonen, K. Life Cycle Assessment Study of Starch Products for the European Starch Industry Association (Starch Europe): Sector Study; Flemish Institute for Technological Research NV (“VITO”): Flanders, Belgium, 2015.

4. Robak, K.; Balcerek, M. Review of second generation bioethanol production from residual biomass. Food Technol. Biotechnol. 2018, 56, 174-187. [CrossRef] [PubMed]

5. Li, A.; Antizar-Ladislao, B.; Khraisheh, M. Bioconversion of municipal solid waste to glucose for bio-ethanol production. Bioprocess Biosyst. Eng. 2007, 30, 189-196. [CrossRef] [PubMed]

6. Pleissner, D.; Lin, C.S.K. Valorisation of food waste in biotechnological processes. Sustain. Chem. Process. 2013, 1, 21. [CrossRef]

7. Lam, W.C.; Pleissner, D.; Lin, C.S.K. Production of fungal glucoamylase for glucose production from food waste. Biomolecules 2013, 3, 651-661. [CrossRef]

8. Uçkun Kiran, E.; Trzcinski, A.P. Optimizing the Conversion of Food Waste to Sugars using Fungal Enzymes. EC Microbiol. 2017, 8, 98-112.

9. Díaz, A.I.; Laca, A.; Laca, A.; Díaz, M. Treatment of supermarket vegetable wastes to be used as alternative substrates in bioprocesses. Waste Manag. 2017, 67, 59-66. [CrossRef]

10. Vynios, D.H.; Papaioannou, D.A.; Filos, G.; Karigiannis, G.; Tziala, T.; Lagios, G. Enzymatic production of glucose from waste paper. BioResources 2009, 4, 509-521.

11. Liu, S.; Lu, H.; Hu, R.; Shupe, A.; Lin, L.; Liang, B. A sustainable woody biomass biorefinery. Biotechnol. Adv. 2012, 30, 785-810. [CrossRef]

12. Duque, A.; Manzanares, P.; Ballesteros, I.; Ballesteros, M. Steam Explosion as Lignocellulosic Biomass Pretreatment. In Biomass Fractionation Technologies for a Lignocellulosic Feedstock Based Biorefinery; Elsevier: Amsterdam, The Netherlands, 2016; pp. 349-368. ISBN 9780128025611.

13. Binder, J.B.; Raines, R.T. Fermentable sugars by chemical hydrolysis of biomass. Proc. Natl. Acad. Sci. USA 2010, 107, 4516-4521. [CrossRef]

14. Lali, A.M.; Odaneth, A.A.; Victoria, J.J.; Choudhari, V.G.; Wadekar, P.C.; Patil, M.L.; Patil, P.S. Process for Production of Pure Glucose from Cellulose. WO Patent 013684, 26 January 2017.

15. Roy, P.; Tokuyasu, K.; Orikasa, T.; Nakamura, N.; Shiina, T. A Review of Life Cycle Assessment (LCA) of Bioethanol from Lignocellulosic Biomass. Jpn. Agric. Res. Q. 2012, 46, 41-57. [CrossRef]

16. Prasad, A.; Sotenko, M.; Blenkinsopp, T.; Coles, S.R. Life cycle assessment of lignocellulosic biomass pretreatment methods in biofuel production. Int. J. Life Cycle Assess. 2016, 21, 44-50. [CrossRef]

17. Patel, M.; Zhang, X.; Kumar, A. Techno-economic and life cycle assessment on lignocellulosic biomass thermochemical conversion technologies: A review. Renew. Sustain. Energy Rev. 2016, 53, 1486-1499. [CrossRef]

18. Pierobon, F.; Eastin, I.L.; Ganguly, I. Life cycle assessment of residual lignocellulosic biomass-based jet fuel with activated carbon and lignosulfonate as co-products. Biotechnol. Biofuels 2018, 11, 139. [CrossRef] [PubMed] 
19. Renouf, M.A.; Wegener, M.K.; Nielsen, L.K. An environmental life cycle assessment comparing Australian sugarcane with US corn and UK sugar beet as producers of sugars for fermentation. Biomass Bioenergy 2008, 32, 1144-1155. [CrossRef]

20. Tsiropoulos, I.; Cok, B.; Patel, M.K. Energy and greenhouse gas assessment of European glucose production from corn-a multiple allocation approach for a key ingredient of the bio-based economy. J. Clean. Prod. 2013, 43, 182-190. [CrossRef]

21. Moncada, J.; Vural Gursel, I.; Huijgen, W.J.J.; Dijkstra, J.W.; Ramírez, A. Techno-economic and ex-ante environmental assessment of C6 sugars production from spruce and corn. Comparison of organosolv and wet milling technologies. J. Clean. Prod. 2018, 170, 610-624. [CrossRef]

22. Salim, I.; González-García, S.; Feijoo, G.; Moreira, M.T. Assessing the environmental sustainability of glucose from wheat as a fermentation feedstock. J. Environ. Manag. 2019, 247, 323-332. [CrossRef] [PubMed]

23. Morales, M.; Pielhop, T.; Saliba, P.; Hungerbühler, K.; Rudolf von Rohr, P.; Papadokonstantakis, S. Sustainability assessment of glucose production technologies from highly recalcitrant softwood including scavengers. Biofuels Bioprod. Biorefin. 2017, 11, 441-453. [CrossRef]

24. Cherubini, F.; Strømman, A.H.; Ulgiati, S. Influence of allocation methods on the environmental performance of biorefinery products-A case study. Resour. Conserv. Recycl. 2011, 55, 1070-1077. [CrossRef]

25. Nemecek, T.; Kägi, T. Life Cycle Inventories of Agricultural Production Systems; Ecoinvent Centre. Swiss Centre For Life Cycle Inventories: Dübendorf, Zurich, Switzerland, 2007.

26. Davis, R.; Tao, L.; Scarlata, C.; Tan, E.C.D.; Ross, J.; Lukas, J.; Sexton, D. Process Design and Economics for the Conversion of Lignocellulosic Biomass to Hydrocarbons: Dilute-Acid and Enzymatic Deconstruction of Biomass to Sugars and Catalytic Conversion of Sugars to Hydrocarbons Process Design and Economics for the Conversion o; National Renewable Energy Laboratory: Golden, CO, USA, 2015.

27. Dietrich, F.; Gerd, W. Wood: Chemistry, Ultrastructure, Reactions; Walter de Gruyter: Berlin, Germany, 2011.

28. International Organization for Standardization. Environmental Management-Life Cycle AssessmentRequirements and Guidelines; ISO 14044: 2006; ISO: Geneva, Switzerland, 2006; pp. 1-46.

29. Akmalina, R. Environmental Impacts Evaluation of Sorbitol Production from Glucose. Eksergi 2019, 16, 7-12. [CrossRef]

30. Alvira, P.; Ballesteros, M.; Negro, M.J. Bioresource Technology Pretreatment technologies for an efficient bioethanol production process based on enzymatic hydrolysis: A review. Bioresour. Technol. 2010, 101, 4851-4861. [CrossRef] [PubMed]

31. Zhu, J.Y.; Pan, X.J. Woody biomass pretreatment for cellulosic ethanol production: Technology and energy consumption evaluation. Bioresour. Technol. 2010, 101, 4992-5002. [CrossRef] [PubMed]

32. Sims, R.; Taylor, M. From 1st- to 2nd-Generation BioFuel technoloGies. Biofuel Technology; International Energy Agency (IEA): Paris, France, 2008. 